\title{
Understanding primary care providers' perceptions of cancer prevention and screening in a predominantly rural healthcare system in the upper Midwest
}

Daniel M. Saman ${ }^{1 *}$ (D), Kayla M. Walton', Melissa L. Harry', Stephen E. Asche², Anjali R. Truitt², Hillary A. Henzler-Buckingham', Clayton I. Allen', Heidi L. Ekstrom², Patrick J. O'Connor², JoAnn M. Sperl-Hillen², Jeanette Y. Ziegenfuss ${ }^{2}$, Joseph A. Bianco ${ }^{3}$ and Thomas E. Elliott ${ }^{2}$

\begin{abstract}
Background: Cancer is the leading cause of death in the United States, with the burden expected to rise in the coming decades, increasing the need for effective cancer prevention and screening options. The United States Preventive Services Task Force has suggested that a shared decision-making process be used when clinicians and patients discuss cancer screening. The electronic medical record (EMR) often provides only reminders or alerts to primary care providers (PCPs) when screenings are due, a strategy with limited efficacy.

Methods: We administered a cross-sectional electronic survey to PCPs ( $n=165,53 \%$ response rate) at 36 Essentia Health primary care clinics participating in a large, National Cancer Institute-funded study on a cancer prevention clinical decision support (CDS) tool. The survey assessed PCP demographics, perceptions of the EMR's ability to help assess and manage patients' cancer risk, and experience and comfort level discussing cancer screening and prevention with patients.
\end{abstract}

Results: In these predominantly rural clinics, only 49\% of PCPs thought the EMR was well integrated to help assess and manage cancer risk. Both advanced care practitioners and physicians agreed that cancer screening and informed discussion of cancer risks are important; however, only 53\% reported their patients gave cancer screening a high priority relative to other health issues.

Conclusions: The impact of EMR-linked CDS delivered to both patients and PCPs may improve cancer screening, but only if it is easy to use and saves PCPs time.

Keywords: Cancer prevention, Cancer screening, Clinical decision support, Electronic medical record, Primary care provider

\section{Introduction}

Cancer is emerging as the leading cause of death in developed countries [1]. In 2012, one in four deaths was due to cancer in the United States [2]. Risk of cancer increases with age, and due to the aging population, the burden of cancer is expected to increase worldwide in the next few decades $[1,2]$. Thus, many experts, care

\footnotetext{
* Correspondence: Daniel.Saman@EssentiaHealth.org

${ }^{1}$ Essentia Institute of Rural Health, 502 E. Second Street, Duluth, MN 55805, USA

Full list of author information is available at the end of the article
}

delivery systems, and the International Agency for Research on Cancer are pushing for more active cancer prevention and screening options to reduce the growing burden of cancer.

Existing preventive methods, when used, are effective in reducing cancer risk. Tobacco use cessation, a healthy lifestyle, and healthy eating have all been shown to effectively reduce the risk of cancer [1]. For several common cancers, screening does lead to higher survival rates and less overall cancer burden [3]. For example, the updated United States Preventive Services Task Force 
(USPSTF) recommendations for colon cancer screening have significantly improved rates of screening and decreased the incidence of colorectal cancer in different populations [4].

However, cancer screening rates are far from optimal, and a simple recommendation for screening may not be enough to motivate patients to get screened, or patients may not be following through with testing [5]. Preliminary data from 2012 to 2014 among eligible Essentia Health patients aged 11-80 with two or more primary care visits within 36 months showed about two-thirds are up to date on colorectal cancer screening, two-thirds up to date on breast cancer screening, $54 \%$ up to date on cervical cancer screening, and 5\% of males aged 1126 and $20 \%$ of females are up to date on HPV vaccination. The USPSTF has suggested that a shared decision-making (SDM) process be used when discussing screening options [6]. SDM engages the patient as an informed partner to ensure that decisions reflect unique health needs and preferences. Provider-patient interaction plays a critical role in increasing screening adherence [3]. When patients are engaged in the decision-making process, they are more likely to take ownership over the course of action [7]. In addition, SDM has been shown to improve overall patient health and reduce health care costs [8].

One method for improving the quality of recommendations for cancer screening is use of the electronic medical record (EMR) to offer clinical decision support (CDS) tools. CDS tools are electronic systems that attach reminders and alerts to patients' charts when they need certain types of care [9]. They are designed to both help improve direct clinical decision making and address gaps in health care [9-11]. While great emphasis has been placed on CDS tools, limited evidence supports their efficacy. In a 2012 meta-analysis by Bright et al., CDS tools were effective in increasing orders for preventive care services. However, many of these interventions used tools developed for only a few clinics, were not implemented systemwide, or were tied directly to the EMR. Indeed, benefits of CDS are limited, largely due to how it is implemented [11-13]. In a recent review by Rashanov et al. [13], the authors analyzed 162 randomized trials of CDS tools. Of these trials, only $58 \%$ successfully improved patient outcomes or provider care. CDS tools were significantly more likely to succeed if they gave advice to both providers and patients, required providers to explain why they overrode an alert, were developed by the study authors rather than a third party, and involved both the provider and the patient.

Despite existing CDS tools and the noted benefits of SDM, primary care providers (PCPs) often fail to include patients in the decision-making process for cancer screening [14-17]. There are often multiple or even conflicting recommendations for optimal care, and many patients are not well informed when making cancer screening decisions [18]. When discussion of cancer screening does occur, patients are often informed of the benefits-but not the risks. In their survey, Hoffman et al. [18] found that less than half of patients who had recently undergone cancer screening were able to correctly answer even one question about it. This suggests a serious gap in care delivery that could compromise a patient's involvement in SDM. However, a study by Bryan et al. [19] suggested that educating PCPs about updated breast cancer screening recommendations and options increased their knowledge and changed their recommendations. The authors also noted that PCPs' attitudes toward SDM and their comfort with discussing breast cancer screening significantly increased postintervention. It appears that PCPs' lack of SDM may be due in part to lack of education and comfort, but few studies have addressed this gap.

This survey was conducted as part of our larger National Cancer Institute-funded cancer CDS study to understand providers' perceptions regarding cancer prevention prior to the implementation of our EMR-based CDS. The aims of this exploratory survey were threefold: 1) assess PCPs' opinions about current EMR and cancer prevention CDS tools; 2) assess PCPs' knowledge of current cancer screening and prevention recommendations; and 3) identify strategies that could narrow observed gaps in cancer prevention and screening by physicians and advanced care practitioners.

\section{Methods}

\section{Study participants}

Study participants included 335 PCPs practicing in at least one of 36 Essentia Health primary care clinics participating in a cancer prevention and screening CDS randomized controlled trial that included 24 intervention clinics and 12 control clinics. Essentia Health is a predominantly rural, upper Midwestern, integrated health care system. The survey was administered before implementation of a cancer prevention and screening CDS in the 24 intervention clinics. PCPs included physicians (family practice or internal medicine), advanced care practitioners (adult, pediatric, family, or geriatric), and physician assistants who provide ongoing care for 25 or more patients who met study eligibility criteria or worked $50 \%$ or more effort as a PCP. A follow-up survey focusing on CDS usage and SDM is currently being planned to determine whether perceptions on cancer prevention have changed following usage of the CDS.

\section{Survey instrument}

The survey instrument queried PCPs in areas such as demographics, views on EMR-based CDS, tobacco 
cessation, weight management, risk calculators, SDM between patients and PCPs, SDM tools for cancer prevention and screening, and medical group commitment and preparedness to maximize cancer prevention interventions. Survey questions were developed by the study team (Additional file 1) or adapted from validated instruments used in the National Survey of Primary Care Physicians' Recommendations \& Practice for Breast, Cervical, Colorectal, \& Lung Cancer Screening [20] and the System Usability Scale (SUS) [21].

\section{Data collection}

The survey was administered electronically from November 2, 2017 to January 24, 2018. PCPs in the 36 study clinics were initially emailed an invitation to take part in the survey signed by the site principal investigator. PCPs were then emailed as many as seven reminders if they did not complete the survey. Survey completion implied PCP consent. This study was reviewed and approved by the Essentia Health Institutional Review Board.

\section{Data analysis}

Descriptive and bivariate data analyses were conducted in SAS v. 9.4 [22] by SA. Bivariate tests of association compared responses from physicians and advanced care practitioners (physician assistants and advanced care practitioners). These included cross-tabulations reporting chi-square $\left(\chi^{2}\right)$, Fisher's exact test when cell counts were $<$ 5, and Cramer's $V\left(\phi_{c}\right)$ and Phi $(\phi)$ for assessing the strength of associations with nominal data. Categorical responses with more than two options were recoded into binary variables for analysis (e.g., "Sometimes/Never" and "Always/Usually"; "Very effective" and "Somewhat/Not effective/Don't know"; "Very/Somewhat uncomfortable" and "Somewhat/Very comfortable"; "Somewhat/Not helpful" and "Very helpful"; "Strongly/Somewhat agree" and "Neither agree nor disagree/Strongly/Somewhat disagree"; "Medium/Low priority" and "High priority"; "Somewhat/ Not prepared" and "Very prepared"). Tests were twotailed, with an alpha of 05 .

\section{Results}

\section{Descriptive data}

Of the 335 potential study participants, 312 had functioning email addresses signifying they were still employed by Essentia Health. Of those 312 PCPs, 165 (53\%) returned either a fully or partially completed survey. As shown in Tables 1, 62\% of respondents were women, advanced care practitioners were more likely to be women than were physicians, $\chi^{2}(1, n=164)=42.24$, $p<.001, \phi=0.51$, and physicians were significantly more likely to be older than advanced care practitioners, $\chi^{2}$ (3, $n=164)=19.88, p<.001, \phi_{c}=0.35$. Physicians were also
Table 1 Respondent Demographics

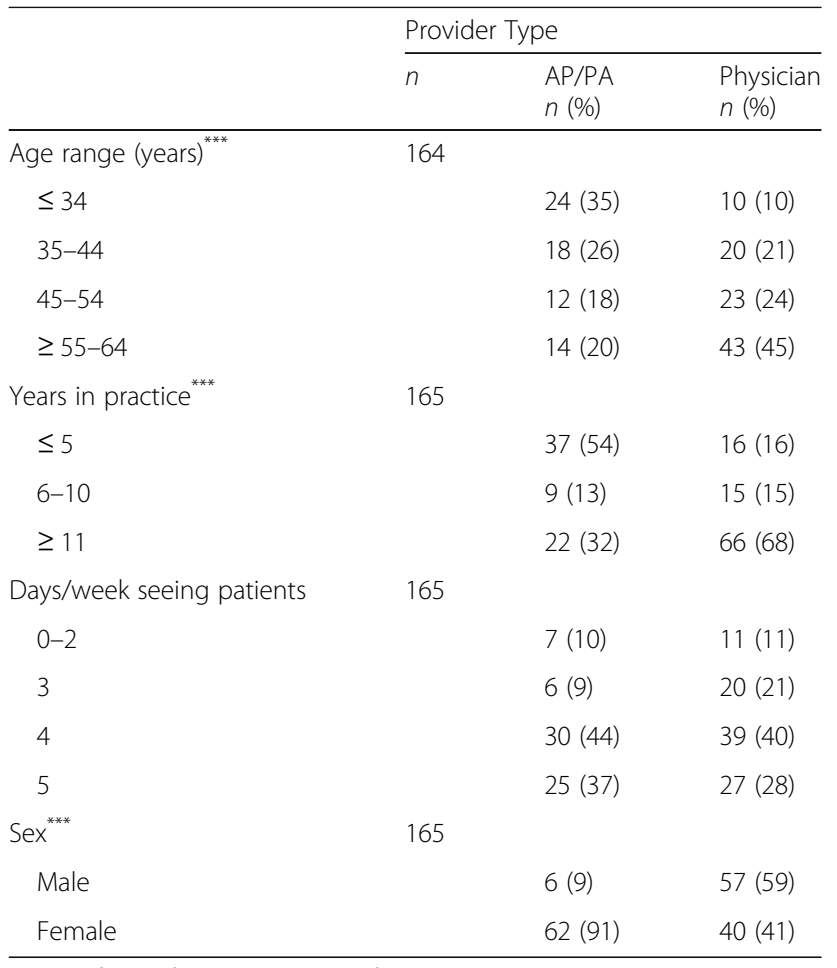

AP/PA Advanced care practitioner/physician assistant

${ }^{* * *} P<.001$.

significantly more likely to have been in practice longer than advanced care practitioners, with $68 \%$ of physicians in practice 11 years or more, compared with $32 \%$ of advanced care practitioners, $\chi^{2}(2, n=165)=27.58$, $p<.001, \phi_{c}=0.41$.

\section{Cancer screening and prevention}

When asked about health priorities, 53\% of PCPs reported their patients give cancer screening a high priority in relation to other health services, but physicians (63\%) reported their patients were significantly more likely to place high priority on cancer screening than those of advanced care practitioners $(40 \%)\left(\chi^{2}(1, n=\right.$ $165)=8.63, p=.003, \phi=0.23)$. PCPs were also asked about having adequate time to discuss different cancer screening options (Table 2), including cancer prevention

Table 2 Provider Perspectives on Time to Discuss Cancer Screening

\begin{tabular}{lllllll}
\hline How often do you have & \multicolumn{5}{c}{ Response Options } \\
\cline { 2 - 7 } $\begin{array}{l}\text { enough time to discuss } \\
\text { the following with your } \\
\text { patients? }\end{array}$ & $\begin{array}{l}n \\
\text { Never } \\
n(\%)\end{array}$ & $\begin{array}{l}\text { Sometimes } \\
n(\%)\end{array}$ & $\begin{array}{l}\text { Usually } \\
n(\%)\end{array}$ & $\begin{array}{l}\text { Always } \\
n(\%)\end{array}$ \\
\hline Breast Cancer Screening & 153 & $22(15)$ & $87(57)$ & $36(23)$ & $8(5)$ \\
Colon Cancer Screening & 153 & $23(15)$ & $104(68)$ & $22(14)$ & $4(3)$ \\
Lung Cancer Screening & 145 & $7(5)$ & $96(66)$ & $35(24)$ & $7(5)$ \\
Cervical Cancer Screening & 148 & $38(26)$ & $93(63)$ & $13(9)$ & $4(3)$ \\
\hline
\end{tabular}


using the human papillomavirus (HPV) vaccination (Table 3). Most PCPs reported that they do not always have enough time to discuss screening or HPV vaccination with patients (Tables 2 and 3). Seventy-seven percent of PCPs said that patients sometimes do not know about the HPV vaccine, and most (93\%) noted that patients usually or sometimes do not perceive HPV as a serious health threat (Table 3). However, no significant differences were seen between physicians and advanced care practitioners.

When asked about preparedness, 63\% of PCPs reported feeling very prepared to prioritize cancer risk factors and screening and discuss with their patients, compared to $37 \%$ feeling somewhat or not prepared. Overall, 93\% of PCPs said they were very or somewhat comfortable discussing increased cancer risk with overweight or obese patients. However, advanced care practitioners $(13 \%, n=9)$ were significantly more likely to be very or somewhat uncomfortable discussing increased risk of cancer with overweight or obese patients than physicians $(3 \%, n=3 ; p=.03, \phi=0.19)$. There were no significant differences between groups regarding comfort level discussing increased cancer risk with patients who smoke. Overall, 98\% of PCPs felt very or somewhat comfortable discussing this with patients who smoke (not reported in tables).

\section{Electronic medical record}

As shown in Table 4, about $57 \%$ of PCPs somewhat or strongly agreed the EMR was easy to use for helping assess and manage cancer risk. About half (49\%) somewhat or strongly agreed the EMR was well integrated to help assess and manage cancer risk, and 66\% $(n=107)$ either disagreed or were neutral (somewhat disagree, strongly disagree, neither agree nor disagree) with the notion the EMR was easy to learn to use to help manage cancer risk. No significant differences were observed between physicians and advanced care practitioners.

When asked about different functions of the EMR, most PCPs (68\%) noted that the EMR did not alert them when cervical cancer screening was due (Table 5). Thirty-seven percent also said they were not alerted when lung cancer screening was due, and 26\% said they were not alerted when an HPV vaccination was due.
Table 5 also indicates that most PCPs did not think the EMR supported printouts of useful information to help patients identify a preferred screening method or could classify patients based on individual cancer risk scores.

\section{Discussion}

Few studies have assessed PCPs' attitudes about cancer screening and prevention in predominately rural areas. As noted elsewhere, engaging patients through cancer SDM with PCPs is challenging, particularly given current time constraints in primary care [23, 24]. Although $37 \%$ of PCPs were not very prepared to discuss cancer risk factors and screening with patients, less than half (49\%) said that the EMR was well integrated to help assess and manage cancer risk. Moreover, only $57 \%$ of PCPs said that the EMR was easy to use for helping assess and manage cancer risk. While providers generally reported the EMR does well around ordering screenings, the EMR does not calculate individual cancer risk well, and does not allow for printing materials to assist patients in making decisions. These data are somewhat mixed, yet point to the need for a more useful and practical EMR that better helps PCPs make decisions and assess cancer risk for patients.

Only $53 \%$ of respondents said that their patients give cancer screening a high priority in relation to other health services, and this percentage was even lower in advanced care practitioners. This finding could be due to several issues we identified in key informant interviews [24] and through continued engagement with our intervention clinics: lack of time for patients and/or providers to discuss cancer prevention; and patients visiting for acute reasons. Most PCPs also reported that they often do not have enough time to discuss screening or HPV vaccination with patients. This points to the challenges associated with improving rates of cancer prevention and screening in a high-pressure, time-constrained primary care environment $[25,26]$ and supports the need to optimize the EMR to more easily address cancer prevention and screening needs.

We observed few statistically significant differences between physicians and advanced care practitioners in this study. Of note, compared with advanced care practitioners, physicians reported their patients were

Table 3 Provider Perspectives on Human Papillomavirus (HPV) Vaccination

\begin{tabular}{|c|c|c|c|c|c|}
\hline \multirow{2}{*}{$\begin{array}{l}\text { When you talk to patients about HPV vaccination, how often do you } \\
\text { encounter the following? }\end{array}$} & \multicolumn{5}{|c|}{ Response Options } \\
\hline & $n$ & $\begin{array}{l}\text { Always } \\
n(\%)\end{array}$ & $\begin{array}{l}\text { Usually } \\
n(\%)\end{array}$ & $\begin{array}{l}\text { Sometimes } \\
n(\%)\end{array}$ & $\begin{array}{l}\text { Never } \\
n(\%)\end{array}$ \\
\hline Not having enough time to discuss HPV vaccination with my patients & 146 & $5(3)$ & $19(13)$ & $92(63)$ & $30(21)$ \\
\hline Patients who do not want to discuss HPV vaccination & 146 & $1(1)$ & $34(23)$ & $100(68)$ & $11(8)$ \\
\hline Patients who are unaware of HPV vaccination & 145 & $1(1)$ & $19(13)$ & $111(77)$ & $14(10)$ \\
\hline Patients who do not perceive HPV as a serious health threat & 143 & $4(3)$ & $63(44)$ & $70(49)$ & $6(4)$ \\
\hline
\end{tabular}


Table 4 Provider Perspectives on Electronic Medical Record (EMR) Decision Support Effectiveness

\begin{tabular}{|c|c|c|c|c|c|c|}
\hline \multirow[t]{2}{*}{ Survey Questions ${ }^{\mathrm{a}}$} & \multicolumn{6}{|c|}{ Response Options } \\
\hline & $n$ & $\begin{array}{l}\text { Strongly } \\
\text { disagree } \\
n(\%)\end{array}$ & $\begin{array}{l}\text { Somewhat } \\
\text { disagree } \\
n(\%)\end{array}$ & $\begin{array}{l}\text { Neither agree } \\
\text { nor disagree } \\
n(\%)\end{array}$ & $\begin{array}{l}\text { Somewhat } \\
\text { agree } \\
n(\%)\end{array}$ & $\begin{array}{l}\text { Strongly } \\
\text { agree } \\
n(\%)\end{array}$ \\
\hline $\begin{array}{l}\text { Our EMR decision support is easy to use for helping me assess and manage } \\
\text { a patient's cancer risk. }\end{array}$ & 163 & $7(4)$ & $43(26)$ & $21(13)$ & $78(48)$ & $14(9)$ \\
\hline $\begin{array}{l}\text { The various functions in our EMR decision support are well integrated for } \\
\text { helping to assess and manage a patient's cancer risk. }\end{array}$ & 163 & $14(9)$ & $37(23)$ & $31(19)$ & $69(42)$ & $12(7)$ \\
\hline $\begin{array}{l}\text { Most providers easily learn how to use the EMR decision support to help } \\
\text { them manage a patient's cancer risk. }\end{array}$ & 161 & $11(7)$ & $54(34)$ & $42(26)$ & $44(27)$ & $10(6)$ \\
\hline $\begin{array}{l}\text { Our EMR decision support is awkward/cumbersome to use for helping } \\
\text { assess and manage a patient's cancer risk. }\end{array}$ & 163 & $9(6)$ & $29(18)$ & $50(31)$ & $56(34)$ & $19(12)$ \\
\hline
\end{tabular}

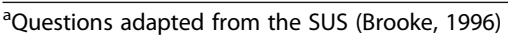

Table 5 Provider Perspectives on the Electronic Medical Record (EMR) for Cancer Prevention and Screening

\begin{tabular}{lll}
\hline Survey Questions & \multicolumn{2}{l}{ Response Options } \\
\cline { 2 - 3 } & $\begin{array}{l}\text { Yes } \\
n(\%)\end{array}$ & $\begin{array}{l}\text { No } \\
n(\%)\end{array}$ \\
\hline The EMR alerts me that this action is due. & $8(5)$ \\
Breast Cancer Screening & $148(95)$ & $105(68)$ \\
Cervical Cancer Screening & $50(32)$ & $14(9)$ \\
Colorectal Cancer Screening & $139(91)$ & $56(37)$ \\
Lung Cancer Screening & $97(63)$ & $40(26)$ \\
HPV Vaccination & $113(74)$ &
\end{tabular}

The EMR makes it easy for me to order the needed service.

$\begin{array}{lll}\text { Breast Cancer Screening } & 130(84) & 24(16) \\ \text { Cervical Cancer Screening } & 92(60) & 61(40) \\ \text { Colorectal Cancer Screening } & 128(84) & 25(16) \\ \text { Lung Cancer Screening } & 98(66) & 51(34) \\ \text { HPV Vaccination } & 113(76) & 35(24)\end{array}$

The EMR enables me to print out materials that help patients identify their preferred screening method.

$\begin{array}{lll}\text { Breast Cancer Screening } & 49(33) & 102(67) \\ \text { Cervical Cancer Screening } & 42(28) & 107(72) \\ \text { Colorectal Cancer Screening } & 55(37) & 93(63) \\ \text { Lung Cancer Screening } & 47(32) & 101(68) \\ \text { HPV Vaccination } & 51(35) & 94(65)\end{array}$

The EMR makes it easy to calculate cancer risks for individual patients.

$\begin{array}{lll}\text { Breast Cancer Screening } & 12(8) & 140(92) \\ \text { Cervical Cancer Screening } & 11(7) & 141(93) \\ \text { Colorectal Cancer Screening } & 16(11) & 137(89) \\ \text { Lung Cancer Screening } & 29(19) & 122(81) \\ \text { HPV Vaccination } & 19(12) & 133(87)\end{array}$

HPV Human papillomavirus significantly more likely to place high priority on cancer screening, and physicians were more comfortable discussing increased risk of cancer with overweight or obese patients. The relative similarities in perceptions between PCPs and advance care practitioners in other areas may be due to statewide initiatives such as Minnesota Community Measurement [27], quality standards for health care systems such as measures of breast and colorectal cancer screening, and Essentia Health's common approach to quality improvement and endorsement of statewide and national quality measures.

Factors that limit the interpretation of these survey data include nonresponse bias, social desirability responses, and missing data from survey noncompletion. Although we adapted the SUS by reducing the number of questions, the SUS-based questions asked in this study provide useful information on PCP perceptions of attitudes towards cancer prevention and screening and satisfaction with current EMR-linked cancer CDS. Results of the survey might differ in other care delivery systems and would be expected to vary over time. The survey results are also limited in generalizability, as we were only interested in understanding perceptions of PCPs within Essentia Health.

Strengths of the study included administering a confidential electronic survey, achieving a high survey response rate, and inviting all PCPs who provide ongoing primary care for 25 or more patients to take the survey. A post-intervention implementation PCP survey is planned for future study years to allow assessment of changes in PCP opinions over time following the use of a developed CDS targeted to improve cancer screening and prevention known as the Cancer Prevention Wizard study $[24,28]$.

\section{Conclusion}

One of a health care organization's many responsibilities is to improve patients' lives through the prevention and early detection of cancer. This burden and opportunity have largely been placed on the shoulders of PCPs, who 
must routinely prioritize and juggle competing patient and clinic demands. As cancer screening and prevention technology improve, risk prediction based on biomarkers will ultimately lead to personalized cancer prevention and detection strategies. As science moves in this direction, the importance of EMR-linked CDS and the need for patients to be well-informed about clinical options will increase dramatically. Although most PCPs said that cancer prevention and screening is important, it is clear that algorithmic personalization of clinical options will become an essential feature of adequate care. The data presented here underscore that the current state of affairs is untenable and suggest that development of more effective and efficient models for cancer prevention CDS and SDM is urgently needed.

\section{Supplementary information}

Supplementary information accompanies this paper at https://doi.org/10. 1186/s12913-019-4872-9.

Additional file 1:. Cancer prevention provider survey. Provider survey questions used in this study.

\section{Abbreviations}

CDS: Clinical Decision Support; EMR: Electronic Medical Record; PCP: Primary Care Provider; SDM: Shared Decision-Making; SUS: System Usability Scale; USPSTF: United States Preventive Services Task Force

\section{Acknowledgements}

The authors would like to acknowledge Mary VanBeusekom for providing writing assistance with this manuscript.

\section{Authors' contributions}

TEE and DMS are the lead Principal Investigators for the main cancer prevention CDS. JAB is a site Co-investigator and a PCP physician in a CDS intervention clinic. PJO and JMS-H are co-investigators for the cancer prevention CDS study, and they co-led the design team in developing and implementing the CDS. HLE is a project manager on the cancer prevention CDS study and has helped with the design and development of the CDS. At the time of this study, $\mathrm{HAH}-\mathrm{B}$ was a site research project coordinator for the cancer prevention CDS study. CA is the site project specialist for the cancer prevention CDS study at Essentia Health. At the time of the study, KMW was the site project manager for the cancer prevention CDS study at Essentia Health. DMS, ART, MLH, HLE, PJO, JMS-H, JYZ, HAH-B, CIA, HLE, JAB, and TEE all contributed in designing and implementing the survey. DMS, KMW, and MLH contributed to writing the manuscript. SEA analyzed and interpreted survey data. All authors read and approved the final manuscript.

\section{Funding}

National Cancer Institute R01CA193396. The funding body had no role in the design of the study, collection, analysis, interpretation of data, or in writing the manuscript.

\section{Availability of data and materials}

The data analyzed during the current study are available from the corresponding author on reasonable request.

\section{Ethics approval and consent to participate}

This study was approved by the Essentia Health Internal Review Board (\# EH16465). Completion of the online survey was considered consent to participate. Survey participants were fully informed of the purpose and nature of the study, that participation was voluntary, that responses would only be reported as an aggregate summary of all participant responses, of any potential benefits and risks, as well as anonymity of responses.
Consent for publication

Not applicable.

\section{Competing interests}

The authors declare that they have no competing interests.

\section{Author details}

${ }^{1}$ Essentia Institute of Rural Health, 502 E. Second Street, Duluth, MN 55805, USA. ${ }^{2}$ HealthPartners Institute, 3311 E. Old Shakopee Road, Bloomington, MN 55425, USA. ${ }^{3}$ Essentia Health - Ely Clinic, 300 W. Conan Street, Ely, MN 55731, USA.

Received: 12 June 2019 Accepted: 24 December 2019

Published online: 30 December 2019

\section{References}

1. Torre LA, Bray F, Siegel RL, Ferlay J, Lortet-Tieulent J, Jemal A. Global cancer statistics, 2012. CA Cancer J Clin. 2015;65(2):87-108.

2. Popat K, McQueen K, Feeley TW. The global burden of cancer. Best Pract Res Clin Anaesthesiol. 2013:27(4):399-408.

3. Peterson EB, Ostroff JS, DuHamel KN, D'Agostino TA, Hernandez M, Canzona MR, et al. Impact of provider-patient communication on cancer screening adherence: a systematic review. Prev Med. 2016;93:96-105.

4. Platz EA. Reducing cancer burden in the population: an overview of epidemiologic evidence to support policies, systems, and environmental changes. Epidemiol Rev. 2017;39(1):1-10.

5. Lafata JE, Cooper G, Divine G, Oja-Tebbe N, Flocke SA. Patient-physician colorectal cancer screening discussion content and patients' use of colorectal cancer screening. Patient Educ Couns. 2014;94(1):76-82.

6. Sheridan SL, Harris RP, Woolf SH. Shared decision-making workgroup of the USPSTF. Shared decision making about screening and chemoprevention: a suggested approach from the U.S. preventive services task force. Am J Prev Med. 2004;26(1):56-66

7. Joosten EA, DeFuentes-Merillas $L$, de Weert GH, Sensky T, van der Staak CP, de Jong CA. Systematic review of the effects of shared decision-making on patient satisfaction, treatment adherence and health status. Psychother Psychosom. 2008;77(4):219-26

8. Legare F, Witteman HO. Shared decision making: examining key elements and barriers to adoption into routine clinical practice. Health Aff (Millwood). 2013;32(2):276-84.

9. Kawamoto K, Houlihan CA, Balas EA, Lobach DF. Improving clinical practice using clinical decision support systems: a systematic review of trials to identify features critical to success. BMJ. 2005;330(7494):765.

10. Bright TJ, Wong A, Dhurjati R, Bristow E, Bastian L, Coeytaux RR, et al. Effect of clinical decision-support systems: a systematic review. Ann Intern Med. 2012:157(1):29-43

11. Garg AX, Adhikari NK, McDonald H, Rosas-Arellano MP, Devereaux PJ, Beyene J, et al. Effects of computerized clinical decision support systems on practitioner performance and patient outcomes: a systematic review. JAMA. 2005;293(10):1223-38.

12. Medlock S, Wyatt JC, Patel VL, Shortliffe EH, Abu-Hanna A. Modeling information flows in clinical decision support: key insights for enhancing system effectiveness. J Am Med Inform Assoc. 2016;23(5):1001-6.

13. Roshanov PS, Fernandes N, Wilczynski JM, Hemens BJ, You JJ, Handler SM, et al. Features of effective computerised clinical decision support systems: meta-regression of 162 randomised trials. BMJ. 2013;346:6657.

14. Bhuyan SS, Chandak A, Gupta N, Isharwal S, LaGrange C, Mahmood A, et al. Patient-provider communication about prostate cancer screening and treatment: new evidence from the health information national trends survey. Am J Mens Health. 2017;11(1):134-46.

15. Dunn AS, Shridharani KV, Lou W, Bernstein J, Horowitz CR. Physician-patient discussions of controversial cancer screening tests. Am J Prev Med. 2001; 20(2):130-4

16. Guerra CE, Jacobs SE, Holmes JH, Shea JA. Are physicians discussing prostate cancer screening with their patients and why or why not? A pilot study. J Gen Intern Med. 2007;22(7):901-7.

17. Han PK, Kobrin S, Breen N, Joseph DA, Li J, Frosch DL, et al. National evidence on the use of shared decision making in prostate-specific antigen screening. Ann Fam Med. 2013;11(4):306-14 
18. Hoffman RM, Lewis CL, Pignone MP, Couper MP, Barry MJ, Elmore JG, et al. Decision-making processes for breast, colorectal, and prostate cancer screening: the DECISIONS survey. Med Decis Mak. 2010;30(5 Suppl):53S-64S.

19. Bryan TJ, Estrada CA, Castiglioni A, Snyder ED. Impact of an educational intervention on provider knowledge, attitudes, and comfort level regarding counseling women ages $40-49$ about breast cancer screening. J Multidiscip Healthc. 2015;8:209-16.

20. National Cancer Institute (2018). National survey of primary care physicians' recommendations \& practice for breast, cervical, colorectal, \& lung cancer screening. Retrieved from https:/healthcaredelivery.cancer.gov/screening_rp/.

21. Brooke J. SUS: a 'quick and dirty' usability scale. In: Jordan PW, Thomas B, Weerdmeester BA, McClelland AL, editors. Usability evaluation in industry. London: Taylor and Francis; 1996.

22. SAS Instititute Inc. (2013). Version 9.4. Cary, North Carolina, USA.

23. Sifri R, Salzman B, Cunningham A, Silverio A, Zale M, Talerico C. Primary care providers' attitudes and practices regarding cancer screening in older adults. Popul Health Manag. 2018;22(4):315-20.

24. Harry ML, Truitt AR, Saman DM, Henzler-Buckingham HA, Allen Cl, Walton $\mathrm{KM}$, et al. Barriers and facilitators to implementing cancer prevention clinical decision support in primary care: a qualitative study. BMC Health Serv Res. 2019;19:534.

25. Caverly TJ, Hayward RA, Burke JF. Much to do with nothing: microsimulation study on time management in primary care. BMJ. 2018;363: k4983.

26. Yarnall KS, Pollak Kl, Ostbye T, Krause KM, Michener JL. Primary care: is there enough time for prevention? Am J Public Health. 2003;93(4):635-41.

27. MN Community Measurement. (2017). Data Files, Analytics and Reports. Retrieved from http://mncm.org/services-solutions/data-analytics-and-reports/

28. Sperl-Hillen JM, Rossom RC, Kharbanda EO, Gold R, Geissal ED, Elliott TE, Desai JR, Rindal DB, Saman DM, Waring SC, Margolis KL, O'Connor PJ. Priorities wizard: multisite web-based primary care clinical decision support improved chronic care outcomes with high use rates and high clinician satisfaction rates. eGems. 2019:7(1):9.

\section{Publisher's Note}

Springer Nature remains neutral with regard to jurisdictional claims in published maps and institutional affiliations.

Ready to submit your research? Choose BMC and benefit from:

- fast, convenient online submission

- thorough peer review by experienced researchers in your field

- rapid publication on acceptance

- support for research data, including large and complex data types

- gold Open Access which fosters wider collaboration and increased citations

- maximum visibility for your research: over $100 \mathrm{M}$ website views per year

At $\mathrm{BMC}$, research is always in progress.

Learn more biomedcentral.com/submissions 